\title{
LANDSLIDE SUSCEPTIBILITY MAPPING ALONG NATIONAL HIGHWAY-6, HOA BINH PROVINCE, VIETNAM USING FREQUENCY RATIO MODEL AND GIS
}

\author{
Ha Thi Hang ${ }^{1}$, Pham Duy Hoa ${ }^{1}$ *Vu Ngoc Tru ${ }^{1}$ and Nguyen Viet Phuong ${ }^{1}$ \\ ${ }^{1}$ Faculty of Bridges and Roads, National University of Civil Engineering, Vietnam \\ *Corresponding Author, Received: 04 June 2021, Revised: 13 July 2021, Accepted: 26 July 2021
}

\begin{abstract}
The landslide has happened quite frequently on National Highway 6 (NH6) and causes damage to both property and life every year. Whereas, detailed landslide susceptibility maps are rarely available on this road. The application of the Frequency Ratio (FR) method and GIS allows for faster, cheaper, more efficient and easily updated landslide susceptibility area determination. This paper presents a landslide susceptibility map along NH6 by using the FR method and GIS. The input data layers include eight main factors that cause landslides, which have collected from various sources. The FR value for each class was calculated based on the spatial relationships between the landslide inventory and landslide influencing factors, then integrated into the GIS environment to produce a landslide susceptibility map. This map was classified into five levels, including very low, low, moderate, high and very high. The validation result of the frequency ratio model is fairly good (AUC $=0.738)$. The developed landslide susceptibility map can help organizers and decisionmakers give early warning to people who have lived along this route and improve the planning of construction and land-use change.
\end{abstract}

Keywords: Landslide susceptibility map, Frequency ratio, GIS, National Highway-6, Vietnam

\section{INTRODUCTION}

The landslide is one of the most common natural disasters occurring along mountainous roads, which cause great economic and human losses. The landslide describes any down-slope movement of soil and rock under the direct influence of gravity [1]. There are many different reasons which cause landslides and rainfall is a vital factor. In Vietnam, landslides frequently occur on cut slopes along the mountainous roads during the rainy season [2]. Especially, many mountainous roads are the only routes which connect to many different areas. Therefore, they play an important role in transportation, economic development and military [3], [4]. Although many engineering solutions (eg. slope stability insurance, new material replacement) were proposed and conducted to reduce landslide hazards on these roads [5], [6], the landslides have still happened on these routes quite frequently. Landslide susceptibility maps can provide a measure of the potential hazard within an area. Meanwhile, these susceptibility maps on these mountainous roads are rarely available. Thus, it is necessary to predict landslide susceptible areas on mountainous roads to reduce landslide damages through proper preparation and/or mitigation.

Landslide susceptibility can be defined as the tendency for a landslide to be generated in a specific area in the future [7]. During the period 2010-2013, many different techniques and methods for landslide susceptibility assessment in the Hoa Binh province of Vietnam have been conducted widely, such as the statistical index and the logistic regression methods [8], a frequency ratio method [9] and support vector machines [10]. Generally, these approaches have provided a reliable landslide susceptibility map for the whole Hoa Binh province. The spatial resolution of input thematic layers in these researches ranged from $30 \mathrm{~m}$ to $50 \mathrm{~m}$, therefore, these research results have only been suitable for the province scale. For NH6 in the Hoa Binh province of Vietnam, the latest study has indicated the spatial prediction of the landslide distribution along this road by using novel hybrid models [11]. Seven novel hybrid models were used in this research, however, it required users to have specific knowledge about machine learning algorithms, statistics, software and have prolonged data processing. Whereas, the frequency ratio (FR) model is the simple bivariate statistical analysis method and is an effective and fast method for the landslide susceptibility assessment. In general, the FR model procedure is easy to understand and run, is often contrasted with other models for landslide susceptibility mapping [12]. According to that, many studies have mainly focused on landslide susceptibility assessment within local scales. There are not many researches using this method for landslide susceptibility map on mountainous roads. In [13], the landslide susceptibility mapping along the mountainous road in India was built using 
frequency ratio (FR) and weight of evidence (WoE) methods. Nine input factors were used to assess. This research also showed the FR method has better accuracy than the WoE method [13]. In recent years, the Geographical Information Systems (GIS) has been seen as a powerful analysis tool for landslide studies [7] because of its capability for combining landslide inventories with other geoenvironmental factors [8]. In this study, the frequency ratio method in the GIS environment was conducted to generate a landslide susceptibility map along NH6, Hoa Binh province of Vietnam.

\section{RESEARCH SIGNIFICANCE}

In the northwestern mountainous of Vietnam, detailed landslide susceptibility maps on the mountainous roads are rarely available. Whereas, the mountainous roads often stretch through many different types of terrain and frequently landslide occurrences, so the landslide susceptibility map needs to be updated continuously and accurately. For the first time, the FR method has been applied to develop a landslide susceptibility map along NH6 in the Hoa Binh province of Vietnam with many advantages, such as quickly, effectively and easily updated every year. Especially, it has not required deep knowledge about machine learning algorithms, software or computer modelling. This study can help organizers and decision-makers give early warning to people who have lived along this road, formulate and implement the landslide mitigation strategies, and improve the planning of construction and land-use change.

\section{METHODOLOGY}

\subsection{Study Area}

NH-6 is the only important route that connects Hanoi Capital to the Northwest mountainous provinces of Vietnam, including Hoa Binh, Son La and Dien Bien. NH-6 passes through Hoa Binh province covering about $115 \mathrm{~km}$ length from Km38 to $\mathrm{Km} 153$ through six districts (Fig.1). Hoa Binh province lies between the latitudes of $20^{0} 19^{\prime} \mathrm{N}-$ $21^{\circ} 08^{\prime} \mathrm{N}$, and the longitudes of $104^{0} 48^{\prime} \mathrm{E}-$ $105^{\circ} 40^{\prime} \mathrm{E}$. The topography of the area is hilly with narrow valleys. Geologically NH-6 passes through different lithology units. Most of them have discrete structures.The average monthly rainfall at the Hoa Binh province varies from about $180 \mathrm{~mm}$ during the dry season to over $1200 \mathrm{~mm}$ during the rainy season. Because of the inconvenient terrain and geology conditions, NH6 has faced landslide disaster regularly every year.

In this study, the buffer of National Highway-6 is quite wide, about $3 \mathrm{~km}$ because most of this route is located between the high mountains and the low valleys, so the range of the landslide occurrence is very large. This problem has also been validated by field survey and historical statistical data of NH6 manager units.

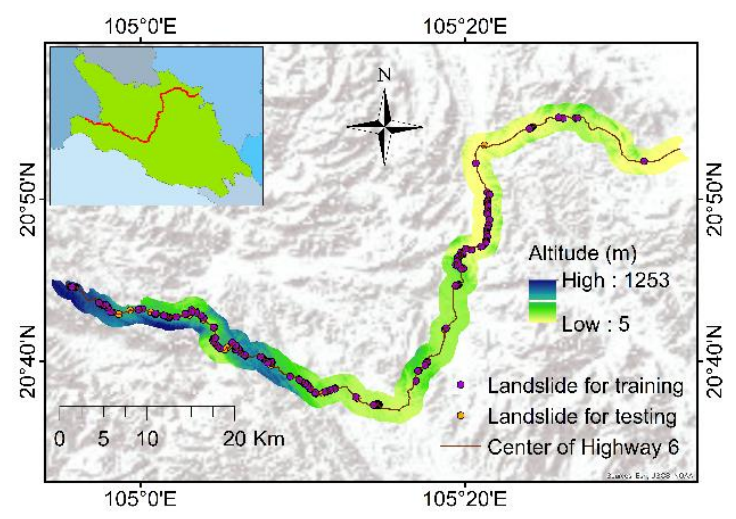

Fig.1 Landslide inventory map along NH-6

\subsection{Landslide Inventory Map}

The landslide inventory map is the most important factor in the landslide assessment procedure. It describes and provides the spatial distribution of existing landslides. In this study, a landslide inventory map was built with 235 landslide locations. Meanwhile, 198 landslide locations were investigated by field survey during the period 2017-2019 [14], and 37 landslide locations were also added from historical landslide reports, statistical data of NH6 manager units.

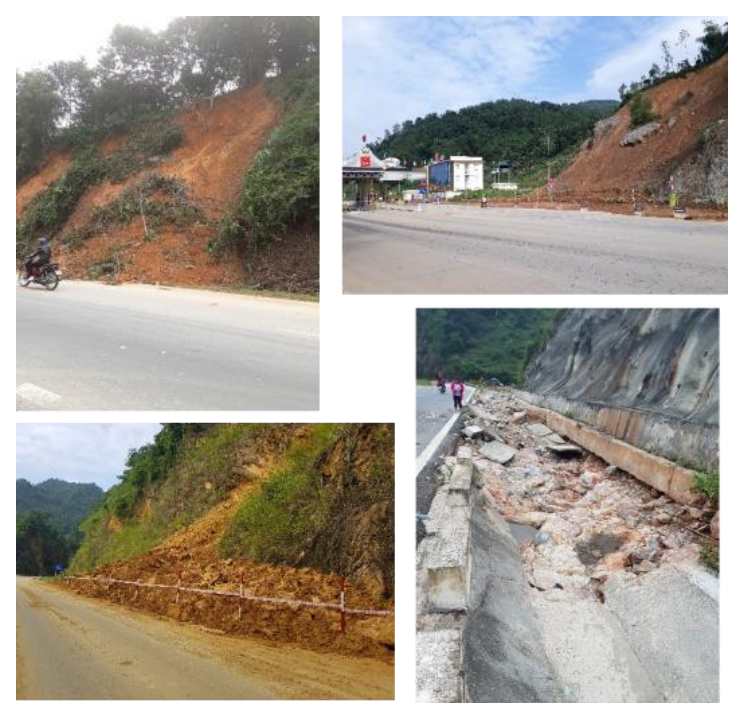

Fig.2 Some typical landslide locations along NH-6 in 2017, 2018, and 2019 field surveys.

The landslide inventory map was randomly partitioned into two datasets: a training dataset with 165 landslide locations (70\% landslide inventory) for building the landslide susceptibility map and a 
testing dataset with 70 landslide locations (30\% remaining landslide inventory) for validating the performance of FR model.

\subsection{Landslide Influencing Factors}

Landslide susceptibility assessment can be measured from the correlation between conditioning factors together with the spatial distribution of the landslide locations. Analyzing landslide influencing factors could control landslide disaster easily [12]. Thus, the determination of landslide influencing factors plays an important role in landslide susceptibility assessment. According to geo-environmental conditions and the available data of the study area, eight landslide influencing factors was considered in this study, including elevation, slope angle, rainfall, lithology, deeply separated density, weathering crust, drainage density and land use. Elevation, slope angle, deeply separated density and drainage density have been constructed using DEM which was explored from a Sentinel-1 image with the resolution of $12.5 \mathrm{~m}$ acquired from https://search.asf.alaska.edu/. Land use map was collected and extracted from the Department of Agriculture and Rural Development of Hoa Binh Province at the scale of 1:50,000 in 2016. Similarly, lithological map and weathering crust map were collected and extracted from Hoa Binh lithological and weathering crust maps at a scale of 50,000, which were provided by the Ministry of Natural Resources and Environment of Vietnam. Rainfall map was created using the Inverse Distance Weighted method based on meteorological data in the period of 1999-2019.

\subsection{Landslide Susceptibility Mapping}

The Frequency Ratio (FR) method is one of the simple probabilistic models [15], based on the spatial relationships between the landslide inventory and landslide influencing factors [7]. In this study, the FR method was used for building a landslide susceptibility map along NH-6. A higher FR value reflects a stronger observed spatial relationship between the landslide occurrence and landslide influencing indicator [15].

The FR value for each class of the landslide causative factors is calculated by combining the landslide inventory map and factor map as the following equation:

$$
F R=\frac{E / F}{G / H}
$$

Where $\mathrm{E}$ is the number of pixels with landslide for each influencing factor class, $\mathrm{F}$ is the number of all pixels in total the research area. $G$ is the number of landslide pixels in each landslide influencing indicator class, $\mathrm{H}$ is the number of all landslide pixels in total the research area.

Whereafter, a Landslide Susceptibility Index (LSI) map was generated by summing all the FR values of $\mathrm{n}$ factors using the following formula [15]:

$$
L S I=F r_{1}+F r_{2}+\ldots+F r_{n}
$$

This LSI map is reclassified to develop a landslide susceptibility map. LSI shows the degree of susceptibility of the area to landslide occurrences. According to that, the LSI value greater than 1 indicates a greater landslide susceptibility and in reverse [12].

\subsection{Validation of The Frequency Ratio Model}

The area under the receiver operation characteristic (ROC) curve (AUC) can be used to assess the prediction accuracy qualitatively. The AUC approach is the most popular statistic method for most of the model performance assessment of landslide [8], [9], [10]. Thus, the performance of the used model in this study has been evaluated using the area under the curve (AUC) approach.

The area under the success rate curve represents the relationship between the percentage of landslide susceptibility map and the percentage of landslide pixels used for the training process [9]. The higher the AUC value is, the better performance of the FR model is. Generally, the performance of a model is good when $0.8<$ AUC $<0.9$ and acceptable when $0.7<\mathrm{AUC}<0.8$ [8], [9].

\section{RESULTS AND DISCUSSION}

\subsection{The FR Values of Landslide Influencing Factors}

The landslide inventory map with 165 landslide locations (70\% landslide inventory) has been overlaid separately with each thematic data layer to calculate the frequency ratio values (FR) of used eight landslide conditioning factors. The calculated weights of the landslide influencing factors are given in Table 1.

Landslides occurrences increase with increasing terrain slope and elevation. Thus, in terrain slope and elevation layers, the obtained frequency ratio has higher values in higher elevation and bigger slope classes. The lithology and weathering crust layers also significantly have an influence on the spatial distribution of landslides on NH6. The Acidmagma rocks, the Carbonate sedimentary rocks and Quaternary sedimentary rocks in the lithology layer are most prone for landslides with a frequency ratio of 2.930, 1.450 and 1.242 , respectively. 
Table 1 Spatial relationships between landslide influencing factors and landslide events using the frequency ratio model.

\begin{tabular}{|c|c|c|c|c|c|c|}
\hline Data layer & Class & Class pixel & $\begin{array}{c}\% \text { class } \\
\text { pixels }(\mathrm{c})\end{array}$ & $\begin{array}{l}\text { Landslide } \\
\text { pixels }\end{array}$ & $\begin{array}{c}\% \\
\text { Landslide } \\
\text { pixels (d) }\end{array}$ & $\mathrm{FR}(\mathrm{d} / \mathrm{c})$ \\
\hline \multirow{5}{*}{$\begin{array}{l}\text { Elevation } \\
\quad(\mathrm{m})\end{array}$} & $5.0-230.0$ & 694189 & 0.34 & 8281.25 & 0.23 & 0.660 \\
\hline & $230.0-473.0$ & 695907 & 0.35 & 9687.5 & 0.27 & 0.770 \\
\hline & $473.0-869.0$ & 259597 & 0.13 & 8281.25 & 0.23 & 1.764 \\
\hline & $869.0-1017.0$ & 219798 & 0.11 & 6718.75 & 0.18 & 1.690 \\
\hline & $1017.0-1253.0$ & 143253 & 0.07 & 3437.5 & 0.09 & 1.327 \\
\hline \multirow{5}{*}{$\begin{array}{c}\text { Slope } \\
\text { (degree) }\end{array}$} & $0-14.4$ & 718900 & 0.36 & 10781.25 & 0.30 & 0.829 \\
\hline & $14.4-28.2$ & 483352 & 0.24 & 8125 & 0.22 & 0.929 \\
\hline & $28.2-40.2$ & 437646 & 0.22 & 8125 & 0.22 & 1.026 \\
\hline & $40.2-59.2$ & 274542 & 0.14 & 6875 & 0.19 & 1.384 \\
\hline & $59.2-78.3$ & 98304 & 0.05 & 2500 & 0.07 & 1.406 \\
\hline \multirow{5}{*}{ Lithology } & $\begin{array}{c}\text { Quaternary } \\
\text { sedimentary rocks }\end{array}$ & 311135 & 0.16 & 7031.25 & 0.19 & 1.242 \\
\hline & $\begin{array}{c}\text { Carbonate } \\
\text { sedimentary rocks }\end{array}$ & 668904 & 0.33 & 17656.25 & 0.48 & 1.450 \\
\hline & $\begin{array}{l}\text { Sedimentary rocks } \\
\text { rich alumosilicate }\end{array}$ & 874756 & 0.44 & 7812.5 & 0.21 & 0.491 \\
\hline & Acid-magma rocks & 20507 & 0.01 & 1093.75 & 0.03 & 2.930 \\
\hline & Mafic erupted rocks & 124746 & 0.06 & 2812.5 & 0.08 & 1.239 \\
\hline \multirow{5}{*}{ Rainfall } & $1401-1528$ & 178293 & 0.09 & 5781.25 & 0.16 & 1.793 \\
\hline & $1528-1587$ & 428804 & 0.21 & 13593.75 & 0.37 & 1.753 \\
\hline & $1587-1641$ & 79840 & 0.04 & 1406.25 & 0.04 & 0.974 \\
\hline & $1641-1703$ & 87172 & 0.04 & 1718.75 & 0.05 & 1.090 \\
\hline & $1703-1764$ & 1238664 & 0.62 & 13906.25 & 0.38 & 0.621 \\
\hline \multirow{4}{*}{$\begin{array}{l}\text { Weathering } \\
\text { crust }\end{array}$} & Sialferit & 895245 & 0.45 & 8906.25 & 0.24 & 0.547 \\
\hline & Ferosialit-Sialferit & 124736 & 0.06 & 2656.25 & 0.07 & 1.170 \\
\hline & Sialferit-Sialit & 668868 & 0.33 & 17812.5 & 0.49 & 1.463 \\
\hline & Ferosialit & 311098 & 0.16 & 7031.25 & 0.19 & 1.242 \\
\hline \multirow{5}{*}{$\begin{array}{c}\text { Deeply } \\
\text { separated } \\
\text { density } \\
(\mathrm{m} / \mathrm{km} 2)\end{array}$} & $0-171$ & 656240 & 0.32 & 8437.5 & 0.23 & 0.731 \\
\hline & $171-288$ & 407134 & 0.20 & 4687.5 & 0.13 & 0.654 \\
\hline & $288-462$ & 610723 & 0.30 & 10625 & 0.29 & 0.988 \\
\hline & $462-690$ & 271559 & 0.13 & 10312.5 & 0.28 & 2.158 \\
\hline & $690-808$ & 122848 & 0.06 & 2343.75 & 0.06 & 1.084 \\
\hline \multirow{5}{*}{$\begin{array}{c}\text { Drainage } \\
\text { density } \\
(\mathrm{km} / \mathrm{km} 2)\end{array}$} & $0-2.17$ & 823161 & 0.39 & 22343.75 & 0.61 & 1.558 \\
\hline & $2.17-4.57$ & 458333 & 0.22 & 7656.25 & 0.21 & 0.959 \\
\hline & $4.57-6.63$ & 452296 & 0.22 & 3437.5 & 0.09 & 0.436 \\
\hline & $6.63-8.03$ & 266581 & 0.13 & 2812.5 & 0.08 & 0.606 \\
\hline & $8.03-9.43$ & 89803 & 0.04 & 156.25 & 0.00 & 0.100 \\
\hline \multirow{8}{*}{ Landuse } & Water bodies & 37972 & 0.02 & 156.25 & 0.00 & 0.208 \\
\hline & Natural forest & 409781 & 0.22 & 11406.25 & 0.31 & 1.410 \\
\hline & $\begin{array}{c}\text { Forest on rocky } \\
\text { mountain }\end{array}$ & 503180 & 0.27 & 11406.25 & 0.31 & 1.148 \\
\hline & Planted forest & 163925 & 0.09 & 5156.25 & 0.14 & 1.593 \\
\hline & Agricultural land & 159606 & 0.09 & 2187.5 & 0.06 & 0.694 \\
\hline & Residential area & 173619 & 0.09 & 2187.5 & 0.06 & 0.638 \\
\hline & Rocky mountain & 191834 & 0.10 & 1250 & 0.03 & 0.330 \\
\hline & Garden land & 204291 & 0.11 & 2187.5 & 0.06 & 0.542 \\
\hline
\end{tabular}


In weathering crust layer, the Sialferit-Sialit, Ferosialit and Ferosialit-Sialferit are the most area for landslides with a frequency ratio of $1.463,1.242$ and 1.170 , respectively.

Landslides occurrences in mountainous roads are often relating to heavy prolonged rains. Therefore, the FR of this layer is quite high in most of the classes.

Similar to the elevation layer, the higher the deeply separated density classes are, the bigger the frequency ratio is.

Drainage density represents the horizontally topographic cleavage due to flow movement and it has a significant influence on the spatial distribution of the landslides.

In land-use factor, the planted forest, natural forest and forest on the rocky mountain have the highest frequency ratio with 1.593, 1.410 and 1.148, respectively.

The agricultural land, residential area and garden land have the same similar frequency ratio. In reverse, rocky mountain and water bodies have the lowest frequency ratio with 0.330 and 0.208 , respectively.

The sum of FR value of used eight landslide influencing factors are given in Table 2.

Table 2 The sum of FR value of eight landslide influencing factors of the study area.

\begin{tabular}{clc}
\hline No & Factors & $\begin{array}{c}\text { Sum of } \\
\text { FR value }\end{array}$ \\
\hline 1 & Elevation (m) & 1.72 \\
2 & Slope (degree) & 1.00 \\
3 & Lithology & 3.21 \\
4 & Rainfall & 1.82 \\
5 & Weathering crust & 2.00 \\
6 & Deeply separated density & 2.59 \\
7 & (m/km2) & 3.85 \\
8 & Drainage density (km/km2) & 2.04 \\
\hline
\end{tabular}

\subsection{Landslide Susceptibility Index Map}

The Weighted Sum tool in ArcGIS was used to overlay the FR of the selected landslide influencing factors classes, to develop a landslide susceptibility index (LSI) map. In this study, the calculated LSI value ranges from 12.7 to 51.1 (Fig.3).

LSI reflects the degree of susceptibility of the area to landslide occurrences. Areas with smaller LSI represent less susceptibility to landslide occurrence and in reverse, areas with higher LSI indicate more susceptibility to landslide occurrence [9].

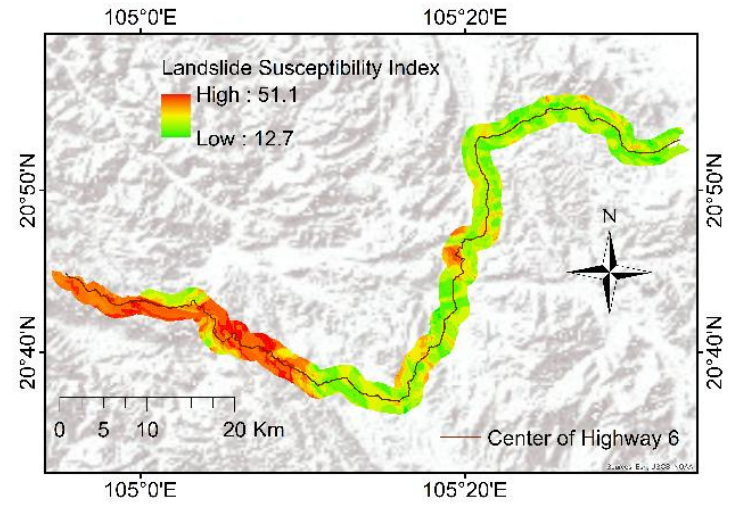

Fig.3 LSI map along NH-6

After that, the LSI map was reclassified into five classes, including very low, low, moderate, high and very high to develop a landslide susceptibility map (Fig.4).

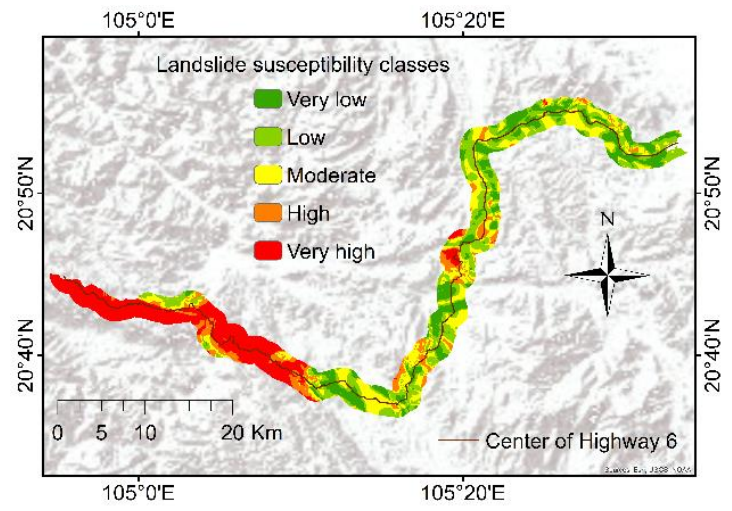

Fig.4 Landslide susceptibility map along NH-6

The classification is useful for estimating the landslide possibility in each class and for visually describing predicted hazardous zones in the study area [7].

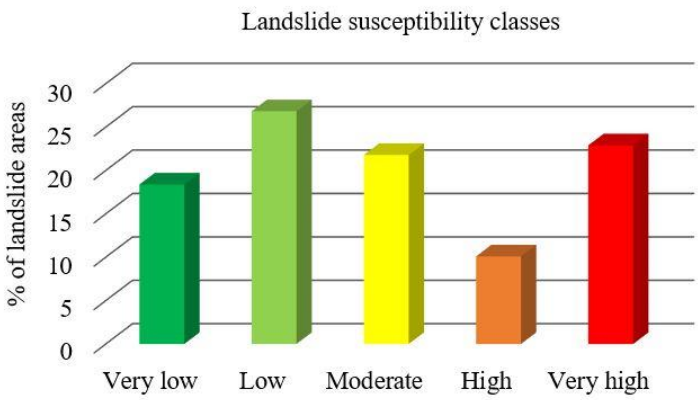

Fig. 5 Histogram of landslide susceptibility areas on NH6 by the FR model

The result map indicated that $18.38 \%$ of the study area is located in the very low susceptibility area, $26.83 \%$ in the low susceptibility area, $21.79 \%$ 
in the moderate susceptibility area, $10.09 \%$ in the high susceptibility area and $22.90 \%$ in the very high susceptibility area (Fig.5).

A landslide susceptibility map can be validated by using data from new landslide locations. In this study, the AUC value of the success rate curve was used to verify the generated landslide susceptibility map.

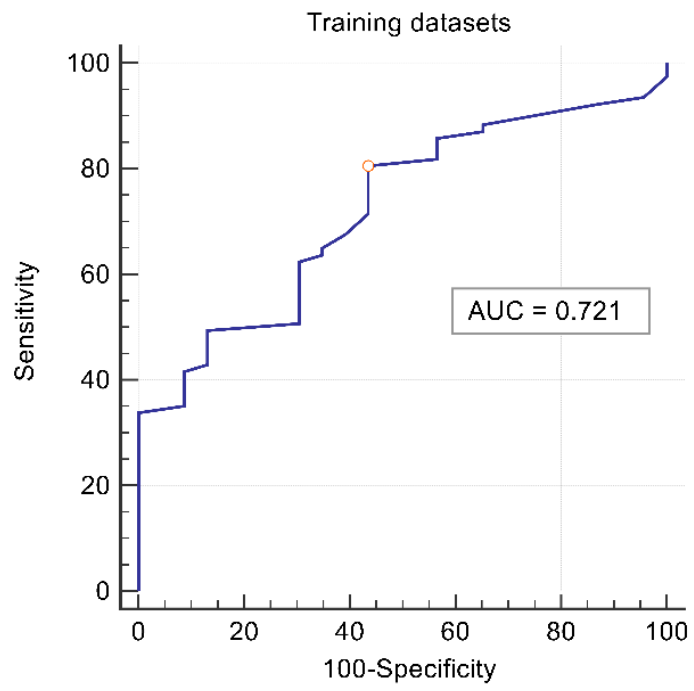

Fig. 6 The validation result of the FR model with the training dataset.

The validation result of the frequency ratio model is fairly good. Meanwhile, the AUC value of the success rate curve is 0.721 with the training dataset (Fig.6) and the AUC value of the success rate curve is 0.738 with the testing dataset (Fig.7), respectively.

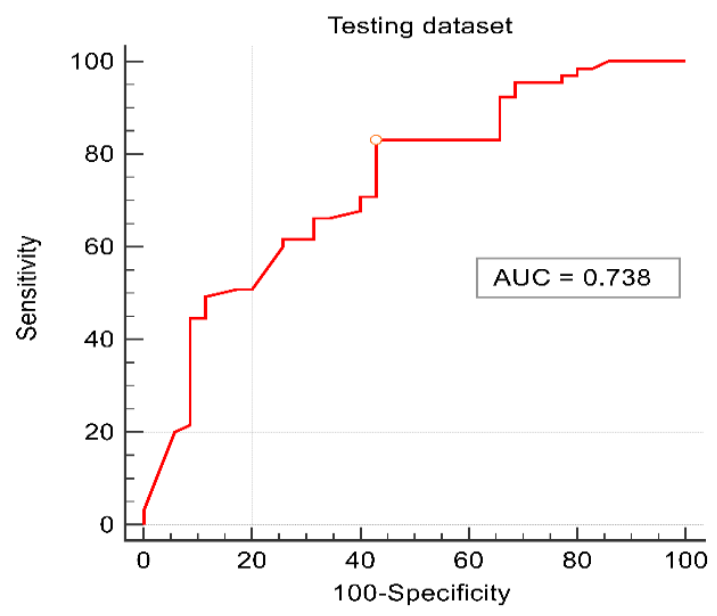

Fig.7 The validation result of the FR model with the testing dataset.

The validation result shows that the landslidesusceptibility map in this study had an accuracy of $73.80 \%$.

\section{CONCLUSION}

In this study, the FR model was used to predict landslide susceptible zones along NH6, where landslides are expected to continue in the future on this road. A total of 235 landslide locations was utilized to construct a landslide inventory map. The spatial relationship between the landslide inventory map and eight landslide causative factors were calculated by the FR technique to develop a landslide susceptibility map on NH6. This result map shows that $32.99 \%$ of the study area is located in the high and very high susceptibility area. The performance of the used model is fairly good (AUC $=0.738$ ).

The result of this research shows that the FR model is an effective, fast and easily updated method for landslide susceptibility assessment on mountainous roads., even in data-scarce areas. In addition, the FR method has the short-time data processing ability. However, the resulting map can be changed if considering the structural factors of the road including the landslide protection methods along both sides of the road. Especially, suitable technical solutions can be proposed from this research result, including the slope stability improvement, warning signs along both sides of the road,... in high and very high susceptible areas. This result needs to conduct with more landslide conditioning factors and consider more other technical parameters of the road.

\section{ACKNOWLEDGMENTS}

This research is funded by National University of Civil Engineering (NUCE) under grant number 23-2019/KHXD-TĐ.

\section{REFERENCES}

[1] Varnes D.J., Landslide Hazard Zonation: A Review of Principles and Practice. United Nation Publisher, 1984, 63p.

[2] Nguyen L.C., Tien P.V. and Do T.N., DeepSeated Rainfall-Induced Landslides on a New Expressway: A Case Study in Vietnam. Landslides, Vol. 17, Issue 2, 2020, pp.395-407.

[3] Chinh Luu, Tran X.H., Pham B.T., Al-Ansari N., Tran Q.T., Duong Q.N., Dao H.N., Nguyen P.L., Nguyen H.D., Ta T.H., Le V.H. and Meding J.V., Framework of spatial flood risk assessment for a case study in Quang Binh province, Vietnam. Sustainability, Vol.12, Issue 7, 2020, pp.3058.

[4] Hang Ha, Chinh Luu, Bui D.Q., Pham D.H., Hoang T., Nguyen V.P., Vu M.T. and Pham B. T., Flash flood susceptibility prediction mapping for a road network using hybrid 
machine learning models. Natural Hazards, 2021, pp.1-24.

[5] Nguyen V. P., Pham D. H., Bui P. D., Bui N. T., and Nguyen D. V. A., Research The Possibility of Using Sea Sand in Roaded Construction in Vietnam. International Journal of GEOMATE, Vol.20, Issue 77, 2021, pp. 123-131.

[6] Bui D. P., Hoang T., Nguyen P. V., Ngo D. V., and Cao C. P., Influence of Distance Between Cement-fly Ash-gravel Piles on The Foundation Treatment in Vietnam. International Journal of GEOMATE, Vol.20, Issue 79, 2021, pp. 104110.

[7] Aleotti P. and Chowdhury R., Landslide Hazard Assessment: Summary Review and New Perspectives. Bulletin of Engineering Geology and the Environment, Vol. 58, Issue 1, 1999, pp.21-44.

[8] Bui D.T., Lofman O., Revhaug I. and Dick O., Landslide Susceptibility Analysis in the Hoa Binh Province of Vietnam Using Statistical Index and Logistic Regression. Natural hazards, Vol. 59, Issue 3, 2011, pp.1413-1444.

[9] Bui D.T., Pradhan B., Lofman O., Revhaug I. and Dick O. B., Landslide Susceptibility Assessment at Hoa Binh Province of Vietnam Using Frequency Ratio Model. Advanced Biomedical Engineering, Vol. 6, 2012, pp.476484.

[10] Bui D.T., Pradhan B., Lofman O., Revhaug I. and Dick O.B., Application of Support Vector Machines in Landslide Susceptibility Assessment for the Hoa Binh Province (Vietnam) with Kernel Functions Analysis. Proceedings of $6^{\text {th }}$
International Congress on Environmental Modelling and Software, 2012, 9p.

[11] Hang H.T., Tung H., Hoa P.D., Phuong N.V., Phong T.V., Costache, R., Nguyen H.D., Amiri M., Le H.A., Le H.V., Prakash I. and Pham B.T., Spatial Prediction of Landslides Along National Highway-6, Hoa Binh Province, Vietnam Using Novel Hybrid Models. Geocarto International, 2021, pp.1-26.

[12] Hong H., Pourghasemi H.R. and Pourtaghi Z.S., Landslide Susceptibility Assessment in Lianhua County (China): A Comparison between a Random Forest Data Mining Technique and Bivariate and Multivariate Statistical Models. Geomorphology, Vol. 259, 2016, pp.105-118.

[13] Hussain G., Singh Y., Singh K. and Bhat G. M., Landslide Susceptibility Mapping along National Highway-1 in Jammu and Kashmir State (India). Innovative Infrastructure Solutions, Vol. 4, Issue 1, 2019, pp. 1-17.

[14] Hang H. T., Landslide Vulnerability Zonation Mapping Using GIS and Remote Sensing Methodology: A Case Study on Highway 6, Hoa Binh Province. International Symposium on Geoinformatics for Spatial Infrastructure Development in Earth and Allied Sciences, 2018, pp. 199-204.

[15] Lee S. and Talib J.A., Probabilistic Landslide Susceptibility and Factor Effect Analysis. Environmental Geology, Vol. 47, Issue 7, 2005, pp.982-990.

Copyright (C) Int. J. of GEOMATE All rights reserved, including making copies unless permission is obtained from the copyright proprietors. 